\title{
Vidas paralelas de los Pueblos del Nuevo Mundo.
}

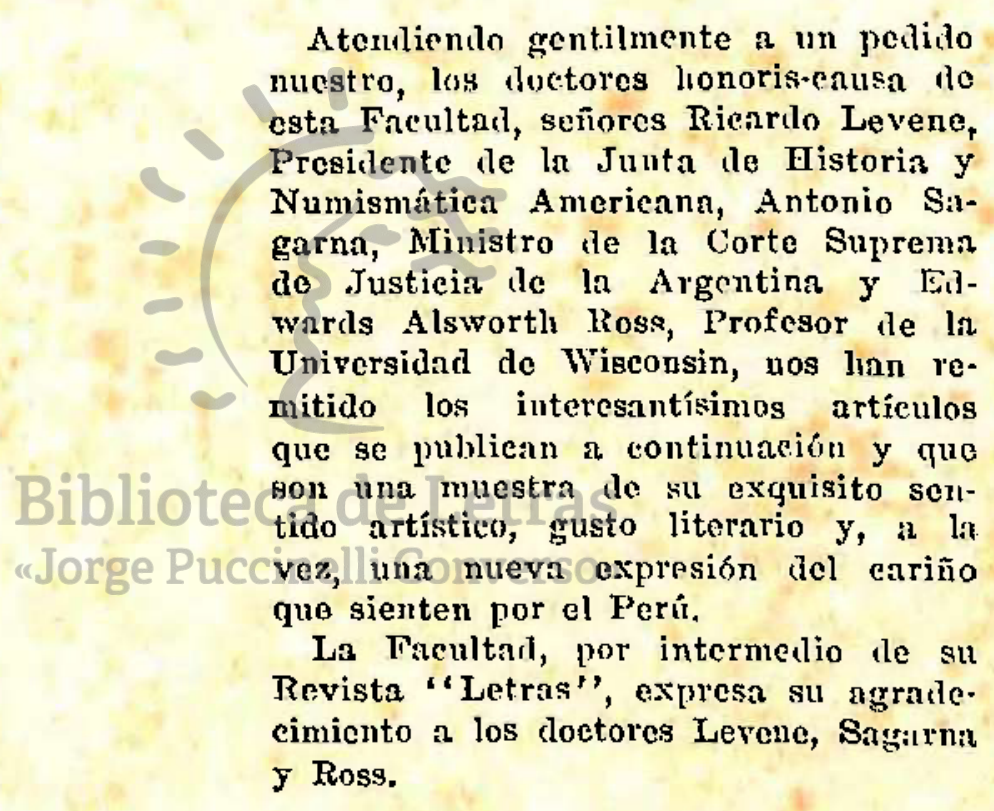

La sociología moderna dedica una de sus ramas al estudio del espiritu creador de la sociedad y expresiones de su psicología, la sicología ideológica o cultural, con unidad sistemática, erigida sobre la base de los modos de pensar, creer y sentir colectivo, su conservación y enriquecimiento, relacionando estos hechos del arte, la religión, la ciencia, las letras, el derecho, con la sociología institucional de los grutpos étnicos, económicos y políticos. 
América es un continente nuevo por su propio contenido y su volumen y densidad sociales.

J.a historia soliclaria de sus partes, la política fundada en una ordenada y fecunda denocracia y su diplomacia en la paz; su inexplotada y variada economía y sus inmensas tierras; en fin, su manifiesta vocación por la cultura, con la enseñanza gratuita extendida en todos los grados, son fuerzas con las que América ha despertado su conciencia y estí forjando su destino.

Si decimos que este hombre americano no repite otro hombre del pasado o presente no pretendemos que sea distinto en virtud de características antropológicas irreductibles sino porque ha formado psicológicamente su espíritu con ideas comunes, en otro medio sin la densidad de Europa, menos agudizada la lucha de la vida y con una herencia sin odios históricos. De esta densidad del tejido social europen, forma parte la tradición y organización de su cultura milenaria, en proceso de surgimiento en América.

Una teoría de los espacios libres puede contribuir a explicar la naturaleza moral y social de este hombre de IberoAmérica, con dilatados horizontes ante sío, en la actitud anhelante del que está en el principio de todas las cosas, que tiene mucho por hacer y que lo piensa y lo hace en grande.

La cultura de las naciones se explica en su clima y escenario, como entidades reales $\mathrm{c}$ ideales a la vez que se renueva y supera sin cesar, que es corriente del pasado que arrastra, pero su ímpetu y dirección depende de la labor de los hombres, pudiéndose afirmar que todo pueblo tiene la cultura que se merece.

América ha suministrado la prueba experimental del fracaso de las teorías naturalistas, del positivismo y materialismo histórico del siglo pasado, particularmente las concepciones geográfica, racial y económica.

El concepto según el cual la civilización superior depen- 


\section{$-357-$}

clía del frío y los habitantes de tales regiones estaban llamados a dominar el mundo, ha sido contestado no ya con otra teoría-que habría implicado continuar una polémica sin término en el plano de la especulación pura-sino con los hechos incontrovertibles del Nuevo Mundo, sus florecientes civilizaciones de la zona caliente, Brasil particularmente.

La teoría racial se debate en profunda crisis, porque América es un laboratorio humano que realiza el experimento extraordinario de la colonización de sus inmensos dominios por la inmigración y mezcla de las razas, elaborando un tipo equipado con sus instintos vitales y por los ideales de su espíritu,

Fué el enciclopedista Gustavo Le Bon, quien dijo en sus pretenciosas "Leyes psicológicas de la evolución de los pueblos" que en América había sucumbido un intento de reproducción de la raza latina, por su falta de carácter y de ética, y a quien no le hemos contestado con la palabra mortificante que nos ha dedicado, sino con esta demostración de la pujanza de Ibero-América.

No ha sido tan fácil derribar la construcción del materialismo histórico, o mejor del economismo, porque su error no es total, radica en su sectarismo, como aplicación permanente en todos los tiempos y como preeminencia absoluta del factor económico en relación con otros factores, pero reconocemos la parte de verdad y vida rebosante que contiene en determinado momento de la vida de los pueblos.

El corifeo del economismo histórico en América fué Juan B. Alberdi, que escribió sus primeros trabajos de interpretación económica, paralelamente con los de Carlos Marx, sin conocerlos.

Dos períodos esencialmente diferentes en la historia de nuestra América del Sud distingue Alberdi en las "Bases y puntos de partida para la organización política de la República Argentina": uno que comienza con la Revolución (en 
I 8 ro en América Hispánica y en 1822 en el Brasil) y concluye con la guerra de la independencia contra España y Portugal; y otro que data de esas épocas y termina hacia 185I-1852 (las guerras contra Rosas en unión con Pedro II).

Las constituciones dictadas durante la guerra fueron expresiones de necesidad de ese momeinto histórico, o sea la conveniencia de proclamar y asegurar la independencia. La riqueza, el progreso material, el comercio, la población, la industria, eran cosas accesorias, intereses de segundo orden, mal conocidos y mal estudiados.

Todo ha cambiado ya, dice Alberdi, en 1852. América más práctica que teórica, más reflexiva que entusiasta, por resultado de la madurez y de la experiencia se preocupa de los hechos más que de los hombres y no tanto se fija en los fines como en los medios prácticos de llegar a la verdad de esos fines. Hoy debemos constituirnos, si nos es permitido este lenguaje, para tener población, para tener caminos de hierro, para ver navegados nuestros ríos, para ver opulentos y ricos nuestros Estados.

No vamos a ponemos en la actitudade combatir a Alberdi oponiendo lämoral a la aliqueza, porque consideramos que América debió empezar como él lo proclamó y lo ejecutaron los estadistas: por el desarrollo y robustecimiento corporal.

No se puede hablar del cuerpo social como de los individuos, pero sí de su morfología, su geografía, el territorio, la concentración humana en las ciudades y los medios de comunicación y afirmo que esa etapa del desenvolvimiento material está cumpliéndose con regularidad y extendiéndose progresivamente. Sería grave error descuidar este aspecto de la civilización relacionado con el bienestar de los hombres pero sería funesto al porvenir de estas naciones jóvenes de América, proclamar el valor exclusivo de los postulados de Alberdi, es decir, del bienester material, sin penetrar 
la realidad presente, que es distinta a la de mediados del siglo pasado.

Entonces esa realidad americana era el desierto. La de hoy, por el carácter hetcrogéneo e invertebrado de nuestras masas que van concentrándose y porque estamos en plena tormenta moral exige su claboración con fuerzas del espíritu.

Hace un siglo Alberdi decía que debíamos constituirnos para ser opulentos y hoy debemos hacerlo para que los Estados ya constituídos hagan efectiva una cnérgica y orgánica política educacional.

El materialismo histórico es impotente para explicar la independencia de Ibero-América, historia épica, aspiraciún ascendente hacia la libetrad; es impotente para explicar este florecimiento de cultura, con centros activos de producción intelectual desinteresada, en fin, es impotente para explicar esta paz política de los Estados fundada en la paz indestructible de las conciencias.

Debcmos superar la etapa romántica de la amistad entranclo en la unión de las inteligencias, sin debilitar las fuerzas del corazón.

Tiene enorme innortancia la aplicación de una organizadia política cultural. Este momento de la cordialidad americana puede ser explicada con una palabra que lo dice todo: la palabra revisión. En efecto, estamos revisando lo hecho anteriormente para perfeccionarlo o ampliarlo en algunos casos, para borrar u olvidar en otros, para vivificar las verdades del pasado, trayéndolas al presente en todos los casos, levantando el sentimiento público.

A cstos fines existen las Comisiones revisoras de textos y de la enseñanza-para resolver problemas de forma y fondo, limpiar el lenguaje de palabras mortificantes y corregir el criterio hiperbólico que desfiguran los valores históricos-y a tales objetivos está destinada a servir la iniciativa de crear una Biblioteca de autores selectos del Brasil, 
en ciencias, letras y artes, traducidos al castellano y de autores argentinos traducidos al portugués.

Iniciaremos la gran Biblioteca futura de autores americanos para difundir sus libros en la enseñanza y en el público. Las obras a publicarse serán sintéticas. La literatura y aún la ciencia deben adquirir carácter más condensado que permitirá conquistar el público lector, pues no es el caso limitarnos a difundir las obras únicamente entre profesionales. El autor incomprendido suele ser culpable de su creación difusa o erudita, sin tiempo para sintetizar.

Estamos ante un grave problema. Paúl Valery ha expresado recientemente una opinión desalentadora en el Instituto de Cooperación Intelectual de la Sociedad de las $\mathrm{Na-}$ ciones en Ginebra. Afirma que la lectura lenta y meditativa está condenada a desaparecer por el desorden que provoca en los espíritus la vida moderna. La educación del público se efectúa actualmente, agrega, por medio de lecturas apresuradas e incoherentes, de efectos brutales e imágenes violentas..... Esta dramática realidad obliga a los intelectuales a renovar sus armas. Antes de declararse vencidos por un público que no leedibros, se imponereconocer la parte de error en los que los elaboran sin forma y sin medida. La que nace muerta es toda obra retórica.

La historia de América, está fundada en hechos que van jalonando su evolución fraterna y el concepto de toda esa historia se estructura en una noción, henchida de promesas, la noción de vidas paralelas de estos pueblos del Nuevo Mundo (como Plutarco en la Antigüedad escribió sobre la vida paralela de los grandes hombres) y tal desenvolvimiento sincrónico corresponde a las principales etapas que se han realizado y se cumplen obedeciendo a comunes ideales.

Buenos Aires, Setiembre de I936.

Ricardo Levene. 